\title{
On-line Green Solid Phase Extraction of Trace Rare Earth Elements and Uranium in Environmental Samples and ICP OES Detection
}

\author{
Naeemeh Zari, ${ }^{a}$ Jalal Hassan, ${ }^{*, b}$ Kourosh Tabar-Heydar ${ }^{a}$ and Seyyed H. Ahmadi ${ }^{a}$ \\ ${ }^{a}$ Environmental Chemistry and Green Technology Department, Chemistry and Chemical \\ Engineering Research Center of Iran, 14335-186 Tehran, Iran \\ ${ }^{b}$ Division of Toxicology, Department of Basic Sciences, Faculty of Veterinary Medicine, \\ University of Tehran, Tehran, Iran
}

\begin{abstract}
An on-line solid phase extraction (SPE) method using mini column packed with natural sorbent based on cotton roll dyed by quinalizarin was developed for simultaneously pre-concentration of rare earth elements and uranium at trace levels in environmental samples followed by inductively coupled plasma optical emission spectrometry (ICP OES) determination. Various parameters such as sample and eluent flow rate, sample volume and matrix ions on the method efficiency have been investigated. Under the optimized conditions, the limits of detection (LODs, $3 \sigma$ ) for rare earth elements were in the range of $0.002-0.300 \mu \mathrm{g} \mathrm{L}-1$ and $0.420 \mu \mathrm{g} \mathrm{L} \mathrm{L}^{-1}$ for uranium. The relative standard deviation $(n=5)$ were lower than $6 \%$ except for samarium and uranium. The method was successfully applied for determination of trace rare earth elements and uranium in lake, well, tap water and carbonate mineral samples. The accuracy of the proposed method was validated by add-found method and direct analysis by ICP OES. This method has some advantages such as simplicity, rapidity, green chemistry and high sensitivity.
\end{abstract}

Keywords: on-line solid phase extraction, ICP OES, rare earth elements, uranium, quinalizarin

\section{Introduction}

Nowadays ground water globally has gained more paramount attention. For the protection and safe use of ground water, it is important to know the origin of water and how it is influenced by the environment. The chemical formulation of waters in the continental crust is determined by water-rock interaction. For inspection of this process fact, the rare earth elements (REEs) can be used as tracers. REEs are also of interest in a wide range of fields in geochemistry including magmatic, hydrothermal and low temperature environments. ${ }^{1-3}$ These elements are also being widely used in high technology industries due to their metallurgical, optical and electronic properties. ${ }^{4-7}$ Rare earth elements enhance chlorophyll content and improve photosynthetic rate, so they have been applied as plant regulator for crops. ${ }^{8-10}$ The rising consumption of REEs in different industries have lead to the great amount discharge of them into the environment. The importance of rare earth elements at mentioned field demands their determination accurately and precisely. Recently, studies for determination of REEs

*e-mail: jalalhassan@ut.ac.ir; jalalhassan1355@yahoo.com in natural water samples have increased greatly. Due to low content of REEs in water samples and complexity of matrix (e.g., marine samples) the most common sensitive analytical techniques used, are inductively coupled plasma mass spectrometry (ICP-MS) and inductively coupled plasma optical emission spectrometry (ICP OES). ${ }^{11-17}$ Although ICP-MS has the detection power to determine traces elements at sub $\mu \mathrm{g} \mathrm{L}^{-1}$, it suffers from the problem of isobaric polyatomic interferences and its low tolerance to total dissolved solids (TDS). This technique is very expensive; its maintenance is very difficult and inaccessible for much laboratories. ${ }^{18}$ Low level of rare earth elements in natural water samples is not compatible with limits of detection (LOD) exhibited by ICP OES technique. Also, ICP OES sometimes encounters problems such as signal suppression and clogging of the introduction system as for dissolved solids in natural samples. For these reasons, there is a demand for pre-concentration and separation of REEs as a group from different matrices before determination. For matrix separation and pre-concentration of REEs, solid phase extraction (SPE) in off-line/on-line mode ${ }^{19-25}$ has been usually used more than other separation techniques such as dispersive liquid-liquid microextraction (DLLME), ${ }^{26}$ 
co-precipitation ${ }^{27}$ and cloud point extraction. ${ }^{28}$ On-line SPE mode in comparison with off-line mode has greater efficiency, lower consumption of sample and reagent, improved precision and capability of on field sampling. ${ }^{29,30}$ On-line column pre-concentration systems coupled with ICP OES are based on retention of analytes in mini/ micro column packed with adsorbent that determines the sensitivity and selectivity of the analytical method. The choice of an adsorbent material for SPE can provide simple operation and more flexible working conditions. Many kinds of solid materials for REEs have been reported in the literature. ${ }^{31-34}$

Quinalizarin (1,2,5,8-tetrahydroxyanthraquinone) is an organic compound which is one of many tetrahydroxyanthraquinone isomers that has been frequently utilized as an analytical reagent in metal ions and pharmaceutical analysis. ${ }^{35,36}$

Our research group has previously reported an off-line methodology with octadecyl silica gel modified with quinalizarin prior to ICP OES determination of REEs. ${ }^{37}$ In the present work, a simple on-line procedure for pre-concentration and determination of trace levels REEs and uranium (U) in natural water samples and carbonate mineral by ICP OES is proposed. The mini column is packed with cotton roll dyed by quinalizarin as sorbent material. The operation condition of ICP OES was optimized using experimental design (Box-Behnken) ${ }^{38,39}$ to get better signal to noise ratio.

\section{Experimental}

\section{Instrumentation}

Simultaneous ICP OES (Varian 735-ES, Palo Alto, CA, USA) in radial torch configuration equipped with $\mathrm{V}$-groove nebulizer and charge coupled device (CCD) detector was used for elemental analysis. Control of the spectrometer was provided by PC-based ICP Expert II software (Agilent Technologies, Santa Clara, CA, USA). For pH adjustment a Jenway $3510 \mathrm{pH}$ meter (Staffordshire, UK) was used. A four channel peristaltic pump (accompanying ICP OES instrument) and a six-port rotary valve were used for coupling SPE extraction system to ICP OES instrument.

\section{Standard solution and reagents}

Working standard solutions by further dilution of stock

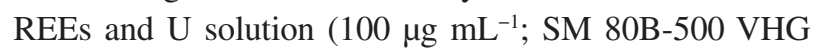
Labs, Manchester, NH, USA) were being prepared to desired concentration daily prior to use. Cotton role was used to prepare the mini column with the dimension of $25 \times 4 \mathrm{~mm}$ (length $\times$ inner diameter). All solvents and reagents were of highest available purity and at least of analytical grade, in which the presence of REEs and $U$ were not detected.

\section{Mini column preparation}

Thirty milligrams of quinalizarin was dissolved in dimethyl sulfoxide (DMSO) and the cotton roll was dyed in prepared solution on heater at temperature of $100{ }^{\circ} \mathrm{C}$ for at least $4 \mathrm{~h}$. Then, it was washed by cold distilled water and dried in an oven. This procedure leads the quinalizarin to be fixed on cotton and the reproducibility of procedure to be guaranteed. This cotton roll was replaced in a sector of an empty cylindrical tube. Finally, the column was connected with polytetrafluoroethylene (PTFE) tubing to a peristaltic pump and rotary valve to form the pre-concentration system.

\section{On-line pre-concentration procedure}

The schematic of integrated extraction/elution set up is shown in Figure 1.
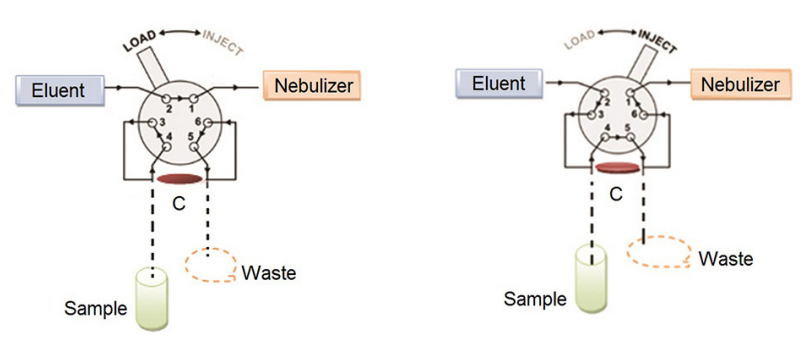

Figure 1. Schematic set up of on-line pre-concentration/determination of desired elements for load and inject process. C: Mini column.

Before loading the mini column, it was conditioned for pre-concentration with buffer solution (ammonium acetate $0.1 \mathrm{~mol} \mathrm{~L}^{-1}$ ) adjusted to $\mathrm{pH} 7$ by $0.1 \mathrm{~mol} \mathrm{~L}^{-1}$ of hydrochloric acid or sodium hydroxide. For extraction procedure, $25 \mathrm{~mL}$ of aqueous sample solution $\left(100 \mu \mathrm{g} \mathrm{L}^{-1}\right)$ of REEs and $\mathrm{U}$ (adjusted to desired $\mathrm{pH}$ ) was loaded on prepared mini column at flow rate of $2 \mathrm{~mL} \mathrm{~min}{ }^{-1}$ with peristaltic pump and rotary valve in load position.

\section{Injection step}

After loading time, the valve was switched to elution position. The retained REEs and $U$ on the cotton roll were eluted with nitric acid $\left(2 \mathrm{~mol} \mathrm{~L}^{-1}\right)$ and were directly introduced to the nebulizer. All the measurements were done as peak height of emission signal. After analyte determination, the injection valve was switched back to loading position and tubing lines were washed by distilled water to eliminate remaining acid. 


\section{Result and Discussion}

In order to optimize the extraction and pre-concentration conditions, some experimental variables were evaluated and optimized using one at a time approach. Type of eluent and $\mathrm{pH}$ were optimized in our off-line previous work. ${ }^{37}$ Sample flow rate, eluent flow rate, breakthrough volume and interfering elements were studied and optimized in this survey. The optimum instrumental conditions for ICP OES were done by experimental design based on Box-Behnken model. Selected analytical wavelength of REEs and $U$ could be seen in the Supplementary Information (Table S1).

\section{ICP OES optimization parameters}

Box-Behnken experimental design was applied to optimize the operating parameters to obtain better sensitivity. The Box-Behnken design (BBD) is an independent quadratic design that does not contain any points at the vertices of the experiment region. The radio frequency of ICP OES (plasma power), nebulizer gas flow rate, sample uptake rate and viewing height were selected as independent variables. Signal to background ratio (SBR) values of REEs were studied as response. Independent variables values are shown in table 1 and the BBD design could be seen in the Supplementary Information (Table S2).

Table 1. Independent variable values

\begin{tabular}{lccc}
\hline Variable & - & Center point & + \\
\hline Viewing height / $\mathrm{mm}$ & 9 & 12 & 15 \\
Radio frequency (RF, plasma power) / $\mathrm{kW}$ & 1 & 1.25 & 1.5 \\
Nebulizer gas flow rate / $\left(\mathrm{L} \mathrm{min}^{-1}\right)$ & 0.6 & 0.8 & 1 \\
Sample uptake & & & \\
rate / $\left(\mathrm{mL} \mathrm{min}^{-1}\right)$ & 1 & 2 & 3 \\
\hline
\end{tabular}

According to the design, each variable was studied at least in 2 levels. The central point was made in 5 replicates adding up to 29 experiments. The experimental data were processed by Design-Expert software version 7.0.40 All measurements were carried out using a test solution with $1 \mathrm{mg} \mathrm{L}^{-1}$ of $\mathrm{La}, \mathrm{Nd}$ and $\mathrm{Yb}$. Response was obtained for geometric mean of results by plotting the mean SBR against radio frequency (RF, plasma power), nebulizer gas flow rate, viewing height and sample uptake rate.

Based on the analysis of variance (ANOVA) results (Table 2), the $p$-values of these parameters, $\mathrm{A}=\mathrm{Rf}$, $\mathrm{B}=$ nebulizer flow, $\mathrm{C}=$ viewing height, $\mathrm{D}=$ sample uptake rate, $\mathrm{AB}, \mathrm{BC}, \mathrm{A}^{2}, \mathrm{~B}^{2}, \mathrm{D}^{2}, \mathrm{AB}^{2}, \mathrm{~B}^{2} \mathrm{C}, \mathrm{B}^{2} \mathrm{D}$, are less than 0.050 and could be named as significant parameters. Furthermore, the values of different $R^{2}$, coefficient of variation, standard deviation and adequate precision, indicated the significance and reliability of the model.

Table 2. Analysis of variance of response

\begin{tabular}{lccc}
\hline Parameter & Value & Parameter & Value \\
\hline Standard deviation & 0.021 & R-squared & 0.9928 \\
Mean & 0.62 & adjusted R-squared & 0.9857 \\
Coefficient of variation / \% & 3.41 & predicted R-squared & 0.8757 \\
Press & 0.11 & adequate precision & 41.367 \\
\hline
\end{tabular}

$3 \mathrm{D}$ response surface plots of $\mathrm{AB}$ and $\mathrm{BC}$ terms are demonstrated in Figures 2 and 3. Maximum area are clear in the figures (red area).

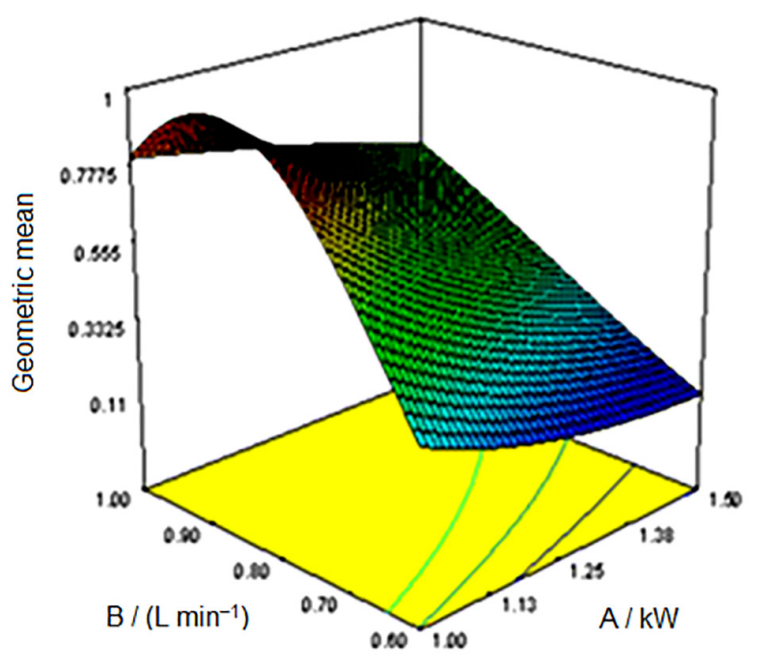

Figure 2. 3D Response surface plots of $A B$ terms. A: Radio frequency (RF) power generator; B: nebulizer flow rate.

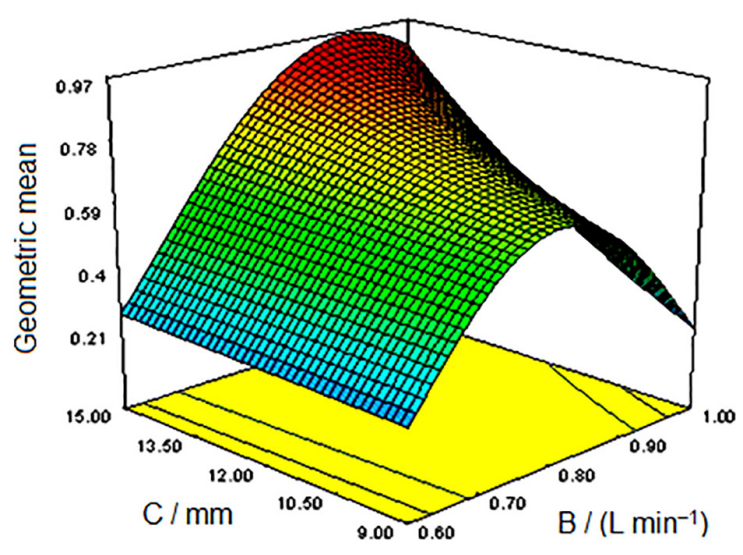

Figure 3. 3D Response surface plots of BC terms. B: Nebulizer flow rate; $\mathrm{C}$ : viewing height.

Plot based, the optimal conditions of selected factors were attained. So, the RF (plasma power) of $1 \mathrm{~kW}$, viewing height of $15 \mathrm{~mm}$ and nebulizer gas flow rate of $0.9 \mathrm{~L} \mathrm{~min}^{-1}$ were used for instrument parameter analysis. 


\section{Effect of sample flow rate}

In an analytical procedure, analysis time is of great attention. As the sample flow rate through mini columns is one of the steps that controls this time, so this parameter was investigated between 1.3 and $6.6 \mathrm{~mL} \mathrm{~min}^{-1}$. According to obtained results (Figure 4), optimal flow rates were in the rage $1.3-2 \mathrm{~mL} \mathrm{~min}^{-1}$. It was assumed that this pre-concentration is kinetic dependent.

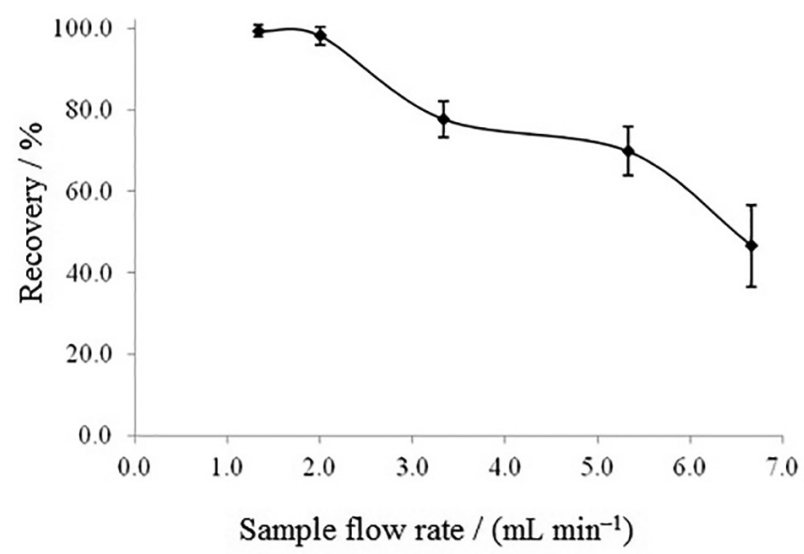

Figure 4. Effect of sample flow rate on the extraction efficiency. Preconcentration conditions: $25 \mathrm{~mL}$ of $100 \mu \mathrm{g} \mathrm{L}^{-1}$ of analytes; $\mathrm{pH}$ 7; eluent: $\mathrm{HNO}_{3} 2 \mathrm{~mol} \mathrm{~L}^{-1}$ with flow rate of $3 \mathrm{~mL} \mathrm{~min}^{-1}$.

\section{Effect of concentration and flow rate of eluent}

REEs and $U$ desorption were studied by increasing the acid concentration from 0.1 up to $3 \mathrm{~mol} \mathrm{~L}^{-1}$. Results were judged based on recovery values. Total desorption was attained at concentration above $1 \mathrm{~mol} \mathrm{~L}^{-1}$. In order to get a guaranteed elution, $2 \mathrm{~mol} \mathrm{~L}^{-1}$ nitric acid solution was chosen as optimum eluent concentration. Also, the influence of eluent flow rate on cations desorption was examined. This modification was done in the range from 0.6-6.6 $\mathrm{mL} \mathrm{min}^{-1}$. Elution flow rate was evaluated in off-line mode first ( $2 \mathrm{~mL}$ eluent was passed through mini column in different rate). Different rates did not show any differences in emission signals. After that, in on-line mode, results showed that analytical signal of desorbed analytes increased

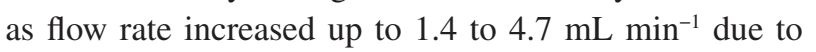
peak narrowing and maximum signal to noise (Figure 5). Improper sample introduction at upper flow rate caused decreasing emission signal.

\section{Interference studies}

The effect of interfering ions on the recovery of REEs and $\mathrm{U}$ up to tolerance level (90\%) was studied on $5 \mu \mathrm{g} \mathrm{\textrm {L } ^ { - 1 }}$ of desired analytes under the corresponding optimum

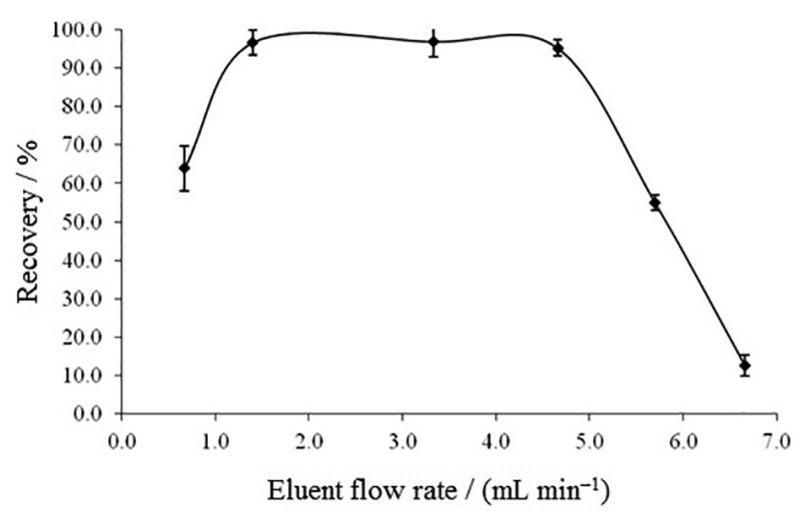

Figure 5. Effect of eluent flow rate on the extraction efficiency. Preconcentration conditions: $25 \mathrm{~mL}$ of $100 \mu \mathrm{g} \mathrm{L}^{-1}$ of analytes; $\mathrm{pH}$ 7; eluent: $\mathrm{HNO}_{3} 2 \mathrm{~mol} \mathrm{~L}^{-1}$.

pre-concentration conditions. A number of common anions such as $\mathrm{Cl}^{-}, \mathrm{Br}^{-}, \mathrm{C}, \mathrm{P}$, and $\mathrm{S}$ were examined up to $100 \mu \mathrm{g} \mathrm{mL}^{-1}$ and no interferences were found. The effect of some base metal cations such as $\mathrm{Cu}^{\mathrm{II}}, \mathrm{Cd}^{\mathrm{II}}, \mathrm{Co}^{\mathrm{II}}, \mathrm{Ti}^{\mathrm{II}}, \mathrm{Cr}^{\mathrm{VI}}$, $\mathrm{Mn}^{\mathrm{II}}, \mathrm{Fe}^{\mathrm{II}}, \mathrm{Zn}^{\mathrm{II}}$ and $\mathrm{Ni}^{\mathrm{II}}$, usually found in water samples, was studied in the range of 1000-5000 folds of desired analyte. The results showed there was not any serious interference on recovery of target analytes. Among alkaline and alkaline earth metal ions $\left(\mathrm{Na}^{+}, \mathrm{K}^{+}, \mathrm{Ca}^{2+}, \mathrm{Mg}^{2+}\right)$, quinalizarin form stable complex with $\mathrm{Mg}^{2+}$. It seems that quinalizarin form more stable complexes with REEs and $\mathrm{U}$ than $\mathrm{Mg}^{2+}$ at $\mathrm{pH} 7$, so no interferences from these common ions were observed in the range of 5000 folds of desired analytes.

\section{Analytical performance}

The dependence of REEs and $U$ recoveries on the volume of real sample was evaluated using $25-400 \mathrm{~mL}$ of sample solution containing $1.0 \mu \mathrm{g}$ of desired elements. The breakthrough volumes of 16 elements were $400 \mathrm{~mL}$ for various ions (Table 3 ). The calibration graphs with optimized conditions were obtained using $25 \mathrm{~mL}$ of multi elements standard solutions in the range of 0.3-30 $\mu \mathrm{g} \mathrm{L} \mathrm{L}^{-1}$. Calibration curves were plotted as emission intensity of extracted analytes against their initial concentration in aqueous phase. Precision of method was evaluated using 5 portions of standard solution of $5 \mu \mathrm{g} \mathrm{L}^{-1}$. The figure of merits of proposed method is summarized in table 3 . The obtained RSD\% values were lower than $6 \%$, except for $\mathrm{Sm}$ and $\mathrm{U}$. The enhancement factors (EF) of analytes were calculated as the respect of the slope of calibration curve after pre-concentration to that obtained by direct injection of standard solution of desired elements.

A comparison with the analytical performance of proposed method and some of the published preconcentration methods for REEs elements were summarized 
Table 3. Figures of merit of the proposed method

\begin{tabular}{|c|c|c|c|c|c|c|c|}
\hline Element & $\begin{array}{l}\text { Enhancement } \\
\text { factor }^{\mathrm{a}}\end{array}$ & $\begin{array}{l}\mathrm{LOD} / \\
\left(\mu \mathrm{g} \mathrm{L}^{-1}\right)\end{array}$ & Calibration equation $^{\mathrm{a}}$ & $\begin{array}{l}\text { Linear range / } \\
\left(\mu \mathrm{g} \mathrm{L}^{-1}\right)\end{array}$ & $\begin{array}{c}\text { Correlation } \\
\text { coefficient }\end{array}$ & $\begin{array}{l}\text { Breakthrough } \\
\text { volume / } \mathrm{mL}\end{array}$ & $\mathrm{RSD}^{\mathrm{b}} / \%$ \\
\hline $\mathrm{Y}$ & 60.7 & 0.005 & $y=970.85 x-152.91$ & $0.3-10$ & 0.9961 & 400 & 4 \\
\hline $\mathrm{La}$ & 58.5 & 0.002 & $y=250.3 x-87.4$ & $0.3-10$ & 0.9952 & 400 & 5 \\
\hline $\mathrm{Ce}$ & 46.2 & 0.130 & $y=89.13 x-3.64$ & $0.3-10$ & 0.9996 & 400 & 3 \\
\hline $\operatorname{Pr}$ & 45.7 & 0.301 & $y=66.32 x+3.37$ & $0.3-10$ & 0.9980 & 400 & 4 \\
\hline $\mathrm{Nd}$ & 40.4 & 0.077 & $y=44.39 x+24.39$ & $0.3-10$ & 0.9970 & 400 & 4 \\
\hline $\mathrm{Sm}$ & 35.8 & 0.171 & $y=60.83 x+0.27$ & $0.3-10$ & 0.9986 & 400 & 16 \\
\hline $\mathrm{Eu}$ & 25.4 & 0.028 & $y=941.3 x+78.02$ & $0.3-5$ & 0.9980 & 400 & 5 \\
\hline $\mathrm{Gd}$ & 53.9 & 0.024 & $y=258.36 x+16.25$ & $0.3-10$ & 0.9997 & 400 & 6 \\
\hline $\mathrm{Tb}$ & 51.1 & 0.286 & $y=100.73 x+27.65$ & $0.3-10$ & 0.9992 & 400 & 5 \\
\hline Dy & 40.4 & 0.120 & $\mathrm{y}=119.97 \mathrm{x}+10.38$ & $0.3-10$ & 0.9998 & 400 & 3 \\
\hline Ho & 44.5 & 0.011 & $y=95.6 x+0.76$ & $0.3-10$ & 0.9990 & 400 & 3 \\
\hline $\mathrm{Er}$ & 51.8 & 0.022 & $y=178.1 x+2.79$ & $0.3-10$ & 0.9990 & 400 & 4 \\
\hline $\mathrm{Tm}$ & 49.2 & 0.145 & $y=362.92 x+37.08$ & $0.3-10$ & 0.9998 & 400 & 3 \\
\hline $\mathrm{Yb}$ & 63.9 & 0.023 & $y=1278.3 x-224.83$ & $0.3-10$ & 0.9964 & 400 & 3 \\
\hline $\mathrm{Lu}$ & 66.7 & 0.005 & $y=568.59 x-7.57$ & $0.3-10$ & 0.9998 & 400 & 3 \\
\hline $\mathrm{U}$ & 11.6 & 0.420 & $y=14.53 x-0.75$ & $1.0-30$ & 0.9989 & 400 & 22 \\
\hline
\end{tabular}

abtained by $25 \mathrm{~mL}$ solution; brelative standard deviation for $\mathrm{n}=5$ replicate measurements at $5 \mu \mathrm{g} \mathrm{L}{ }^{-1}$. LOD: Limit of detection.

Table 4. Comparison of the proposed method and some of the published pre-concentration methods for rare earth elements (REEs)

\begin{tabular}{|c|c|c|c|c|}
\hline Element & Technique & $\mathrm{LOD} /\left(\mathrm{ng} \mathrm{mL}^{-1}\right)$ & $\mathrm{RSD} / \%$ & Reference \\
\hline Pr, Sm, Eu, Gd, Ho, Tb Tm, Yb, Lu, Dy & SPE-ICP OES & $0.01-0.42$ & - & 25 \\
\hline REE & CPE-ICP OES & $0.041-0.045$ & $1-6$ & 28 \\
\hline $\mathrm{Eu}, \mathrm{Gd}, \mathrm{Ho}, \mathrm{La}, \mathrm{Tb}, \mathrm{Yb}, \mathrm{Sm}$ & MWCNT-ICP OES & $3-57$ & $<6$ & 11 \\
\hline REE & magnetic-SPE-ICP-MS & 0.0004-0.0014 & $2-7$ & 16 \\
\hline $\mathrm{La}, \mathrm{Sm}, \mathrm{Nd}$ & SPE-ICP OES & $3.9-7.4$ & $<3$ & 32 \\
\hline REE & on-line-SPE-ICP-MS & 0.0004-0.0025 & $<8$ & 19 \\
\hline REE & MWCNT-ICP-MS & $0.0001-0.0016$ & - & 18 \\
\hline Ce, Dy, La, Sm, Y, U & on-line-SPE-ICP OES & 0.011-0.069 & $1-8$ & 24 \\
\hline REE, U & on-line-SPE-ICP OES & $0.002-0.420$ & $3-6,{ }^{\mathrm{a}} 22^{\mathrm{b}}$ & this study \\
\hline
\end{tabular}

aREE; 'U. CPE: Cloud point extraction; ICP OES: inductively coupled plasma optical emission spectrometry; ICP-MS: inductively coupled plasma mass spectrometry; MWCNT: multi walled carbon nanotube; SPE: solid phase extraction.

in Table 4. It is obvious that this methodology is comparable with other method and in some cases better LODs and precision.

\section{Analysis of real sample}

Certified natural water reference materials are not available for REEs and U. ${ }^{41}$ Thus, the developed method was applied to the pre-concentration and determination of spiked REEs and U in lake, well and tap water. All water samples were collected in polyethylene bottles and acidified up to $\mathrm{pH}=2$ in order to ion metals do not be adsorbed by wall of bottles. Aqueous standard solutions along blank ( $25 \mathrm{~mL}$ deionized water adjusted $\mathrm{pH}$ to 7 by ammonium acetate solution) without matrix optimization were used for calibration and determination of desired elements in samples. The obtained results are presented in Table 5. The Student's $t$-test showed that each mini column supports 20 pre-concentration cycles (data are not shown).

As can be seen, for matrix with high major elements concentration (high TDS, Urumieh Lake, Lorestan Well, Table 6), recoveries have been decreased. For routine analysis correction factor or calibration standard solutions with optimized matrix is applicable. 
Table 5. Results of rare earth elements (REEs) and uranium (U) determination in natural water samples

\begin{tabular}{|c|c|c|c|c|c|c|c|c|c|}
\hline \multirow[b]{2}{*}{ Element } & \multicolumn{3}{|c|}{ Urumieh Lake } & \multicolumn{3}{|c|}{ Lorestan Well } & \multicolumn{3}{|c|}{ Tap water Karaj } \\
\hline & $\begin{array}{l}\text { Added / } \\
\left(\mu \mathrm{g} \mathrm{L}^{-1}\right)\end{array}$ & $\begin{array}{l}\text { Found / } \\
\left(\mu \mathrm{g} \mathrm{L}^{-1}\right)\end{array}$ & $\begin{array}{c}\text { Recovery / } \\
\%\end{array}$ & $\begin{array}{l}\text { Added / } \\
\left(\mu \mathrm{g} \mathrm{L}^{-1}\right)\end{array}$ & $\begin{array}{l}\text { Found / } \\
\left(\mu \mathrm{g} \mathrm{L}^{-1}\right)\end{array}$ & $\begin{array}{c}\text { Recovery / } \\
\%\end{array}$ & $\begin{array}{l}\text { Added / } \\
\left(\mu \mathrm{g} \mathrm{L}^{-1}\right)\end{array}$ & $\begin{array}{l}\text { Found / } \\
\left(\mu \mathrm{g} \mathrm{L}^{-1}\right)\end{array}$ & $\begin{array}{c}\text { Recovery / } \\
\%\end{array}$ \\
\hline $\mathrm{Y}$ & 20.0 & 3.3 & 16 & 5.0 & 3.6 & 73 & 5.0 & 5.0 & 100 \\
\hline $\mathrm{La}$ & 20.0 & 13.4 & 67 & 5.0 & 3.4 & 68 & 5.0 & 4.9 & 98 \\
\hline $\mathrm{Ce}$ & 20.0 & 13.9 & 70 & 5.0 & 3.5 & 70 & 5.0 & 4.5 & 91 \\
\hline $\operatorname{Pr}$ & 20.0 & 14.9 & 75 & 5.0 & 3.3 & 67 & 5.0 & 4.6 & 92 \\
\hline $\mathrm{Nd}$ & 20.0 & 14.7 & 74 & 5.0 & 3.9 & 79 & 5.0 & 4.7 & 94 \\
\hline Sm & 20.0 & 15.1 & 76 & 5.0 & 4.0 & 80 & 5.0 & 4.9 & 98 \\
\hline $\mathrm{Eu}$ & 20.0 & 4.3 & 22 & 5.0 & 4.7 & 94 & 5.0 & 4.8 & 97 \\
\hline Gd & 20.0 & 14.4 & 72 & 5.0 & 4.0 & 80 & 5.0 & 4.9 & 98 \\
\hline $\mathrm{Tb}$ & 20.0 & 14.3 & 72 & 5.0 & 3.9 & 77 & 5.0 & 5.0 & 100 \\
\hline Dy & 20.0 & 14.8 & 74 & 5.0 & 3.4 & 69 & 5.0 & 5.1 & 102 \\
\hline Ho & 20.0 & 14.9 & 75 & 5.0 & 3.8 & 76 & 5.0 & 5.2 & 105 \\
\hline $\mathrm{Er}$ & 20.0 & 15.0 & 75 & 5.0 & 3.9 & 78 & 5.0 & 5.0 & 100 \\
\hline $\mathrm{Tm}$ & 20.0 & 15.0 & 75 & 5.0 & 4.1 & 81 & 5.0 & 5.5 & 111 \\
\hline $\mathrm{Yb}$ & 20.0 & 3.6 & 18 & 5.0 & 4.9 & 89 & 5.0 & 4.7 & 93 \\
\hline $\mathrm{Lu}$ & 20.0 & 14.7 & 74 & 5.0 & 4.1 & 83 & 5.0 & 5.0 & 100 \\
\hline $\mathrm{U}$ & 20.0 & 26.6 & 133 & 5.0 & 5.6 & 112 & 5.0 & 2.8 & 56 \\
\hline
\end{tabular}

Table 6. Urumieh and Lorestan matrix elements ${ }^{\mathrm{a}}$

\begin{tabular}{lcc}
\hline Major element & $\begin{array}{c}\text { Urumieh / } \\
\left(\mu \mathrm{g} \mathrm{mL}^{-1}\right)\end{array}$ & $\begin{array}{c}\text { Lorestan / } \\
\left(\mu \mathrm{g} \mathrm{mL}^{-1}\right)\end{array}$ \\
\hline $\mathrm{Ca}$ & 175.0 & 10.0 \\
$\mathrm{Na}$ & 80.0 & 5.0 \\
$\mathrm{~K}$ & 7.5 & 0.5 \\
$\mathrm{Mg}$ & 70.0 & 10.0 \\
\hline
\end{tabular}

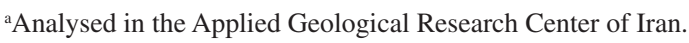

This method was applied for REEs and $\mathrm{U}$ determination in two carbonate mineral samples from central Iran zone (Tabas) too. An aliquot of pulverized sample $(0.5 \mathrm{~g})$ was digested with aqua regia $\left(\mathrm{HCl}: \mathrm{HNO}_{3}, 3: 1\right)$ for $2 \mathrm{~h}$ at $95{ }^{\circ} \mathrm{C}$. The sample was cooled and then diluted up to $50 \mathrm{~mL}$ with deionized water. Digested sample with adjusted $\mathrm{pH}$ was loaded on mini column in optimized flow rate, and then the adsorbed REEs and U were eluted and analyzed by ICP OES. Recoveries are presented in Table 7.

REEs in some samples were not detected directly by ICP OES. So, $2 \mu \mathrm{g} \mathrm{L}^{-1}$ of REEs and U standard solution was

Table 7. Determination of rare earth elements (REEs) ions in carbonate minerals

\begin{tabular}{|c|c|c|c|c|c|c|}
\hline \multirow[b]{2}{*}{ Element } & \multicolumn{3}{|c|}{ Carbonate sample K 29} & \multicolumn{3}{|c|}{ Carbonate sample K 65} \\
\hline & $\begin{array}{c}\text { Found directly by } \\
\text { ICP OES } / \\
\left(\mu \mathrm{g} \mathrm{g}^{-1}\right)\end{array}$ & $\begin{array}{l}\text { Proposed method / } \\
\qquad\left(\mu g g^{-1}\right)\end{array}$ & Recovery / \% & $\begin{array}{c}\text { Found directly by } \\
\text { ICP OES / } \\
\left(\mu \mathrm{g} \mathrm{g}^{-1}\right)\end{array}$ & $\begin{array}{l}\text { Proposed method / } \\
\qquad\left(\mu g g^{-1}\right)\end{array}$ & Recovery / \% \\
\hline $\bar{Y}$ & 0.6 & 0.7 & 114 & 7.5 & 5.5 & 73 \\
\hline $\mathrm{La}$ & 1.36 & 0.9 & 63 & 8 & 7.8 & 98 \\
\hline $\mathrm{Ce}$ & $<\mathrm{LOD}$ & 1.8 & - & 15 & 14.5 & 97 \\
\hline $\operatorname{Pr}$ & $<\mathrm{LOD}$ & 0.5 & - & $<\mathrm{LOD}$ & 2.8 & - \\
\hline $\mathrm{Nd}$ & $<$ LOD & 1.3 & - & 6.2 & 6.5 & 105 \\
\hline $\mathrm{Sm}$ & $<\mathrm{LOD}$ & 0.3 & - & $<\mathrm{LOD}$ & 2.0 & - \\
\hline $\mathrm{Eu}$ & $<$ LOD & 0.4 & - & $<$ LOD & 1.51 & - \\
\hline Gd & $<\mathrm{LOD}$ & 0.6 & - & $<\mathrm{LOD}$ & 2.7 & - \\
\hline $\mathrm{Tb}$ & $<$ LOD & 0.4 & - & $<$ LOD & 1.1 & - \\
\hline Ho & $<\mathrm{LOD}$ & 0.4 & - & $<\mathrm{LOD}$ & 0.7 & - \\
\hline Dy & $<\mathrm{LOD}$ & 0.3 & - & $<\mathrm{LOD}$ & 1.6 & - \\
\hline $\mathrm{Er}$ & 0.6 & 0.5 & 84 & 1.9 & 1.8 & 96 \\
\hline $\mathrm{Tm}$ & $<\mathrm{LOD}$ & 0.4 & - & $<\mathrm{LOD}$ & 1.2 & - \\
\hline $\mathrm{Yb}$ & 0.4 & 0.4 & 95 & 1.1 & 1.2 & 113 \\
\hline $\mathrm{Lu}$ & $<$ LOD & 0.4 & - & $<$ LOD & 1.2 & - \\
\hline $\mathrm{U}$ & 6.8 & 3.2 & 48 & 8.91 & 7.3 & 82 \\
\hline
\end{tabular}

aCP OES: Inductively coupled plasma optical emission spectrometry. K29, K65: code of carbonate minerals from central Iran zone. 
Table 8. Results of some rare earth elements (REEs) in digested sample by add-found method

\begin{tabular}{|c|c|c|c|c|}
\hline \multicolumn{5}{|c|}{ Carbonate sample K 29} \\
\hline Element & $\begin{array}{c}\text { Present in the solution of } \\
\text { digested sample before } \\
\text { loading }^{\mathrm{a}}\left(\mu \mathrm{g} \mathrm{L}^{-1}\right)\end{array}$ & $\begin{array}{l}\text { Added to digested } \\
\text { solution / }\left(\mu \mathrm{g} \mathrm{L} \mathrm{L}^{-1}\right)\end{array}$ & $\begin{array}{l}\text { Found / } \\
\left(\mu \mathrm{g} \mathrm{L}^{-1}\right)\end{array}$ & Recovery / \% \\
\hline$\overline{\mathrm{Ce}}$ & 3.5 & 2 & 6.5 & 118 \\
\hline $\operatorname{Pr}$ & 0.9 & 2 & 3.6 & 122 \\
\hline $\mathrm{Nd}$ & 1.2 & 2 & 5.0 & 155 \\
\hline $\mathrm{Sm}$ & 0.5 & 2 & 3.4 & 134 \\
\hline $\mathrm{Eu}$ & 0.8 & 2 & 4.8 & 166 \\
\hline Gd & 1.1 & 2 & 4.1 & 130 \\
\hline $\mathrm{Tb}$ & 0.9 & 2 & 3.0 & 103 \\
\hline Ho & 0.7 & 2 & 3.3 & 120 \\
\hline Dy & 0.6 & 2 & 3.6 & 139 \\
\hline $\mathrm{Er}$ & 1.2 & 2 & 3.9 & 119 \\
\hline $\mathrm{Tb}$ & 0.9 & 2 & 3.0 & 103 \\
\hline $\mathrm{Tm}$ & 0.7 & 2 & 3.8 & 143 \\
\hline \multicolumn{5}{|c|}{ Carbonate sample K 65} \\
\hline Element & $\begin{array}{c}\text { Present in the solution of } \\
\text { digested sample before } \\
\text { loading }^{\mathrm{a}}\left(\mu \mathrm{g} \mathrm{L}^{-1}\right)\end{array}$ & $\begin{array}{l}\text { Added to digested } \\
\text { solution / }\left(\mu \mathrm{g} \mathrm{L}^{-1}\right)\end{array}$ & $\begin{array}{l}\text { Found / } \\
\left(\mu g L^{-1}\right)\end{array}$ & Recovery / \% \\
\hline $\mathrm{Pr}$ & 5.6 & 2 & 8.2 & 107 \\
\hline $\mathrm{Sm}$ & 4.06 & 2 & 5.8 & 95.7 \\
\hline $\mathrm{Eu}$ & 3.02 & 2 & 4.53 & 90.1 \\
\hline Gd & 5.46 & 2 & 7.53 & 100.9 \\
\hline $\mathrm{Tb}$ & 2.1 & 2 & 3.02 & 73.2 \\
\hline Ho & 1.37 & 2 & 2.45 & 72.7 \\
\hline Dy & 3.2 & 2 & 4.8 & 90.7 \\
\hline $\mathrm{Tm}$ & 1.56 & 2 & 2.7 & 75.8 \\
\hline $\mathrm{Lu}$ & 2.4 & 2 & 3.83 & 86.9 \\
\hline
\end{tabular}

${ }^{\mathrm{a}} 10 \mathrm{~mL}$ of digested sample diluted to $50 \mathrm{~mL}$ (concentrations obtained by proposed method). K 29, K 65: code of carbonate minerals from central Iran zone.

added to the solution of digested sample. The recoveries are demonstrated in Table 8 .

\section{Conclusions}

The proposed on-line solid phase extraction preconcentration methodology using a mini column filled with green sorbent based on dyed cotton roll by quinalizarin is a simple way suitable for determination of 14 REEs and uranium simultaneously in real samples. The procedure offers acceptable accuracy, precision and significant enrichment factor. In addition, this procedure is very straightforward, environment friendly and economical since only quinalizarin without any modification was used for REEs and U pre-concentration simultaneously. This method has feasibility for automation. In this procedure extraction, pre-concentration and elution steps are integrated. The results of real samples analysis showed a strong performance for this method for pre-concentration/ determination of the analytes from real aqueous samples and carbonate minerals.

\section{Supplementary Information}

Supplementary data are available free of charge at http://jbcs.sbq.org.br as PDF file.

\section{Acknowledgments}

The authors of this survey would like to thank the Environmental Chemistry and Green Technology Department of Chemistry and Chemical Engineering Research Center of Iran and ICP OES laboratory in applied geology research center of geological survey of Iran.

\section{References}

1. Murakami, M.; Hamanaka, E.; Takada, T.; Anal. Lett. 2005, 38, 2449.

2. U.S. Geological Survey (USGS); Rare Earth Elements-Critical Research for High Technology, Fact Sheet 087-02, USGS: Virginia, 2002. 
3. Gob, S.; Lodes, A.; Nolde, N.; Bau, M.; Jaccob, D. E.; Markl, G.; Appl. Geochem. 2013, 33, 127.

4. Moldoveana, G. A.; Papangelakis, V. G.; Hydrometallurgy 2012, 117, 71 .

5. Hu, W.; Noreus, D.; J. Alloys Compd. 2003, 356, 734.

6. Gschneidner, K. A.; Pecharsky, V. K.; J. Rare Earths 2007, 24 , 641.

7. Guanming, Q.; Xikun, L.; Tai, Q.; Haitu, Z.; Honghau, Y.; Rutting, M.; J. Rare Earths 2007, 25, 281.

8. Zhang, Z.; Sun, Q.; Ding, S.; Liang, T.; Zhang, Ch.; Yan, J.; Biol. Trace Elem. Res. 2005, 107, 73.

9. Anitha, S.; Challarj, E. S. E.; Saranraj, P.; J. Ecobiotechnol. 2010, $217,01$.

10. Lijun, W.; Tao, L.; Aitang, H.; Shiming, D.; Chaosheng, Z.; Xin, Y.; J. Rare Earths 2005, 23, 747.

11. Liang, P.; Liu, Y.; Guo, L.; Spectrochim. Acta, Part B 2005, 60 , 125.

12. Hakim, L.; Sabarudin, A.; Oshima, M.; Motomizo, S.; Anal. Chim. Acta 2007, 588, 73.

13. Nobuo, S.; Naoki, K.; Hiroshi, I.; Appl. Geochem. 2008, 23, 2955.

14. Dick, D.; Wegner, A.; Gabrielli, P.; Ruth, U.; Barbante, C.; Kriews, M.; Anal. Chim. Acta 2008, 621, 140.

15. Chung, C. H.; Brenner, I.; You, C. F.; Spectrochim. Acta, Part B 2009, 64, 849.

16. Su, S.; Chen, B.; He, M.; Hu, B.; Xiao, Z.; Talanta 2014, 119 , 458.

17. Wen, B.; Shan, X. Q.; Xu, S. G.; Analyst (Cambridge, U. K.) 1999, 124, 621.

18. Cho, J.; Chung, K. W.; Coi, M. S.; Kim, H. J.; Talanta 2012, 99, 369.

19. Hirata, S.; Kajia, T.; Aihara, M.; Honda, K.; Shikino, D.; Talanta 2002, 58, 1185.

20. Maquieira, A.; Elmahdi, H.; Puchades, R.; J. Anal. At. Spectrom. 1999, 11, 99.

21. Rao, T. P.; Kala, R.; Talanta 2004, 63, 949.
22. Karadaş, C.; Kara, D.; Fisher, A.; Anal. Chim. Acta 2011, 689, 184.

23. Huang, C. Z.; Jiang, Z.; Hu, B.; Talanta 2007, 73, 274.

24. Bahramifar, N.; Yamini, Y.; Anal. Chim. Acta 2005, 540, 325.

25. Karadas, C.; Kara, D.; Water, Air, Soil pollut. 2014, 225, 2192.

26. Chandrasekaran, K.; Karunasagar, D.; Arunachalam, J.; J. Chromatogr. A 2008, 118, 59.

27. Taicheng, D.; Tiny, C. H.; Xianjin, Z.; J. Anal. At. Spectrom. 2002, 17, 410 .

28. Li, Y.; Hu, B.; J. Hazard. Mater. 2010, 174, 534.

29. Hang, C. Z.; Hu, B.; Jiang, Z. C.; Zhang, N.; Talanta 2007, 71, 1239.

30. Praveen, R. S.; Daniel, S.; Rao, T. P.; Sampath, S.; Rao, K. S.; Talanta 2006, 70, 437.

31. Dave, S. R.; Kaur, H.; Menon, S. K.; React. Funct. Polym. 2010, $70,692$.

32. Chen, S.; Xiao, M.; Lu, D.; Zhan, X.; Anal. Lett. 2007, 40, 2105.

33. Zeren, F.; Yilmaz, V.; Arslan, Z.; Microchem. J. 2013, $110,178$.

34. Shariati, S.; Yamini, Y.; Faraji, M.; Saleh, A.; Microchim. Acta 2009, 165, 65 .

35. Zanjanchi, M. A.; Noei, H.; Moghimi, M.; Talanta 2006, 70, 933.

36. Cozza, G.; Mazzorana, M.; Papinutto, E.; Biochem. J. 2009, $421,387$.

37. Hassan, J.; Zari, N.; Tabar-Heydar, K.; J. Anal. Chem. 2016, 71,36 .

38. Borokowski, J. J.; Technometrics 1995, 37, 399.

39. Anderson, S. S.; dos Santos, W. N. L.; Ferreira, S. L. C.; Spectrochim. Acta, Part B 2005, 60, 737.

40. Stat-Ease, Inc; Design Expert Software Version 7.0; Minneapolis, USA, 2006.

41. Jarvis, K. K.; Gay, A. L.; Houk, R. S.; Handbook of Inductively Coupled Plasma Mass Spectrometry; Springer: Berlin, 1992.

Submitted: February 18, 2016

Published online: March 14, 2016 